\title{
Refinement of directed melt oxidized structures
}

\author{
ANIRBAN GUHA and V S R MURTHY* \\ Department of Materials and Metallurgical Engineering, Indian Institute of Technology, \\ Kanpur 208016, India \\ MS received 1 May 1996; revised 16 August 1996
}

\begin{abstract}
Composite microstructures obtained via directed melt oxidation can be refined using external reinforcements and alloying additions. The mechanisms responsible for refinement of composite (alumina) microstructure are discussed.
\end{abstract}

Keywords. Oxidation; alloying; composites; microstructure; refinement.

\section{Introduction}

Composites containing interpenetrated network of metal and ceramic phases are produced by directed melt oxidation of liquid aluminium alloys. Commercially, this in situ reaction synthesis is known as DIMOX ${ }^{T M}$ process, which was originally developed by Lanxide Corporation, USA (Newkirk et al 1986, 1987; Salas et al 1991). When a liquid aluminium alloy containing volatile species like $\mathrm{Mg}$, $\mathrm{Zn}$ etc is oxidized, the reaction product, $\mathrm{Al} / \mathrm{Al}_{2} \mathrm{O}_{3}$ composite, builds up on the surface by continuous wicking of liquid metal on to the oxidized surface. Thus, uninterrupted growth of composite occurs until the liquid alloy is entirely exhausted. After the process is complete, the final microstructure consists of uniformly dispersed aluminium and alumina interspersed with macro- and micro-porosities (typically 2-6\%) (figure 1). These composites exhibit good strength and toughness (due to clamping by metal ligaments) compared to alumina, however, residual porosities restrict the maximum possible properties to some extent. By refining the composite structure (mainly alumina), mechanical properties can be improved by uniform and finer distribution of the metallic phase coupled with reduction in pore (defect) size in the structure. Refinement of alumina is feasible either by providing external nucleating sites in the path of oxidation growth front or by modifying the liquid chemistry, which makes nucleation of $\mathrm{Al}_{2} \mathrm{O}_{3}$ easier. Both proposed methodologies are examined considering $\mathrm{Al}-3 \mathrm{Zn}-3 \mathrm{Mg}$ as a base alloy. Salient points are discussed in the light of some experimental observations.

\section{Experimental}

Approximately $24 \mathrm{~mm}$ diameter cylinder bars of $\mathrm{Al}-3 \mathrm{Zn}-3 \mathrm{Mg}(\mathrm{wt} \%)$ alloys with addition of $\mathrm{Ti}$ and $\mathrm{Zr}(0.12 \pm 0.05 \mathrm{wt} \%)$ were prepared using conventional melting techniques. For comparison $\mathrm{Al}-3 \mathrm{Zn}-3 \mathrm{Mg}$ was used without adding any alloying elements. All directed melt oxidation experiments were carried out in leakproof alumina crucibles at $1100^{\circ} \mathrm{C}$ for $16 \mathrm{~h}$. When SiC monofilaments (AVCO SCS-6) were used for infiltration, chopped fibres were placed vertically on top of alloy billet. SiC monofilaments contain a carbon rich surface layer of $\sim 6 \mu \mathrm{m}$. After infiltration, ground powders from the grown composites were used for X-ray diffraction studies. Both

*Author for correspondence 


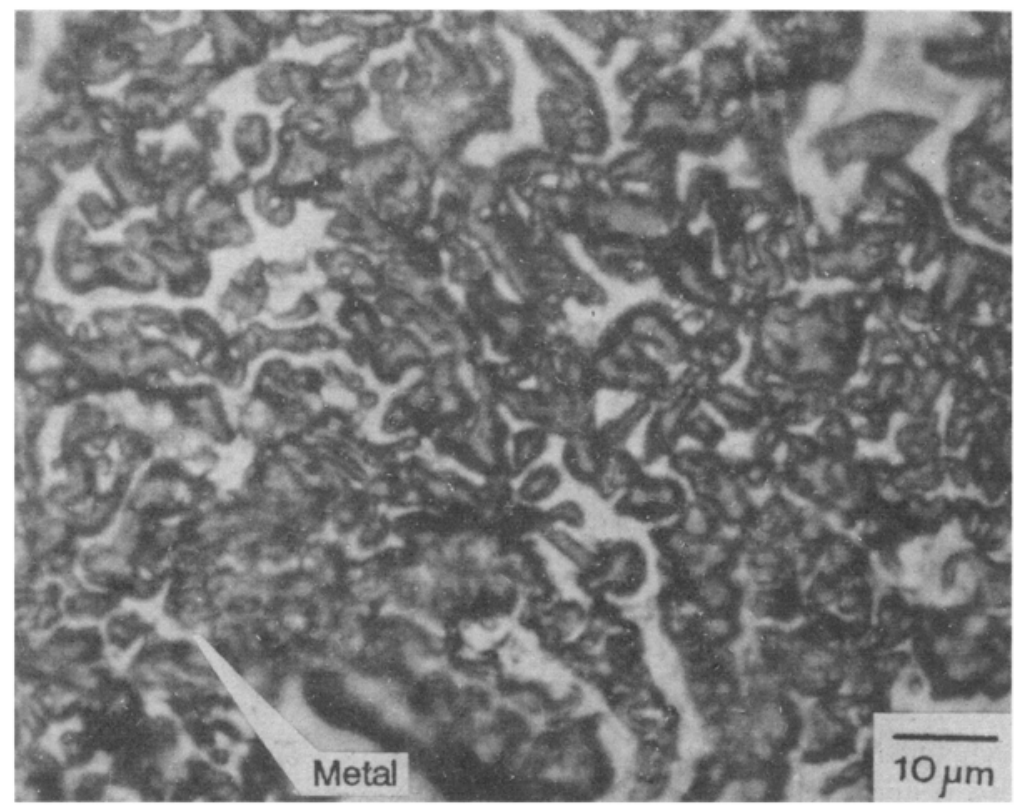

Figure 1. $\mathrm{Al} / \mathrm{Al}_{2} \mathrm{O}_{3}$ structure produced by directed melt oxidation. Dark regions are $\mathrm{Al}_{2} \mathrm{O}_{3}$ and bright regions are $\mathrm{Al}$.

optical and scanning electron microscopes (JEOL 840A) were used for carrying out microstructural studies.

\section{Results and discussion}

As mentioned earlier, heterogeneous nucleating sites can be provided by placing filler materials (oxide or non-oxide reinforcements of any form) in the path of oxidation growth front. Additionally, modified/deposited surface oxide layers of reinforcements can further ease the nucleation process. For instance, silica formed on SiC particulate reinforcements gets reduced by aluminium in the liquid melt $\left(\mathrm{SiO}_{2}+\mathrm{Al} \rightarrow \mathrm{Al}_{2} \mathrm{O}_{3}+\mathrm{Si}\right)$ and secondary nucleation of alumina occurs in addition to the primary $\mathrm{Al}_{2} \mathrm{O}_{3}$ crystals that are growing in the liquid (Dhandapani et al 1994) (figure 2a). Further, the volatile solute atoms $(\mathrm{Mg}, \mathrm{Zn})$ in the liquid alloy vaporize and get deposited as respective oxides (figure $2 \mathrm{~b}$ ). These oxides further undergo displacive reduction reactions like silica, to nucleate $\mathrm{Al}_{2} \mathrm{O}_{3}$ (Murthy and Deepak 1996). When monofilaments are used, in addition to alumina, formation of $\mathrm{Al}_{4} \mathrm{C}_{3}$ is likely via a reaction between unoxidized carbon rich layer and the liquid aluminium alloy. Owing to secondary nucleation, the long columnar type of $\mathrm{Al}_{2} \mathrm{O}_{3}$ crystals in pure alloy oxidation get modified as equiaxed grains (figures $2 \mathrm{c}$ and d). Results here are in confirmation with the findings that were published by Manor et al (1993) and Hanabe et al (1996). However, for uninterrupted liquid metal wicking and oxidation to take place, optimum size and volume fraction of reinforcements need to be defined.

To examine the second option, $\mathrm{Al}-\mathrm{Zn}-\mathrm{Mg}$ alloys with $0.12 \mathrm{wt} \% \mathrm{Ti}$ and $\mathrm{Zr}$ additions were oxidized at $1100^{\circ} \mathrm{C}$ for $16 \mathrm{~h}$ and microstructures were examined using $\mathrm{X}$-ray and 
SEM. The resultant structures were compared with the unalloyed base alloy which was oxidized under similar conditions. X-ray diffraction patterns obtained from various composites are presented in figure 3. By comparing $\mathrm{Al}$ and $\mathrm{Al}_{2} \mathrm{O}_{3}$ peaks in all the alloys, it is evident that the formation of $\mathrm{Al}_{2} \mathrm{O}_{3}$ is dominant in alloyed compositions. The dispersed metal particles are much finer in $\mathrm{Zr}$ alloyed composites compared to
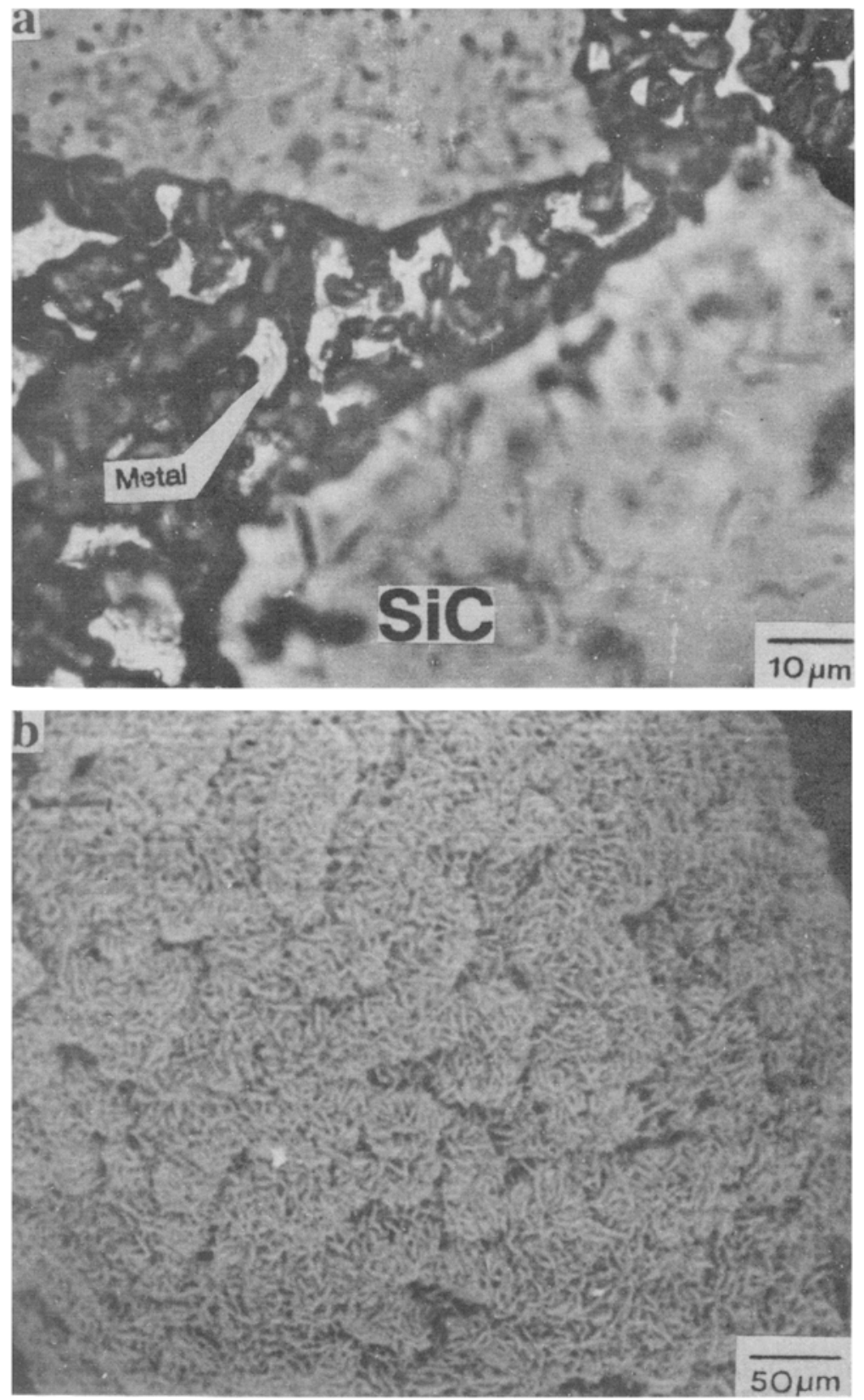

Figure 2. a, b. 

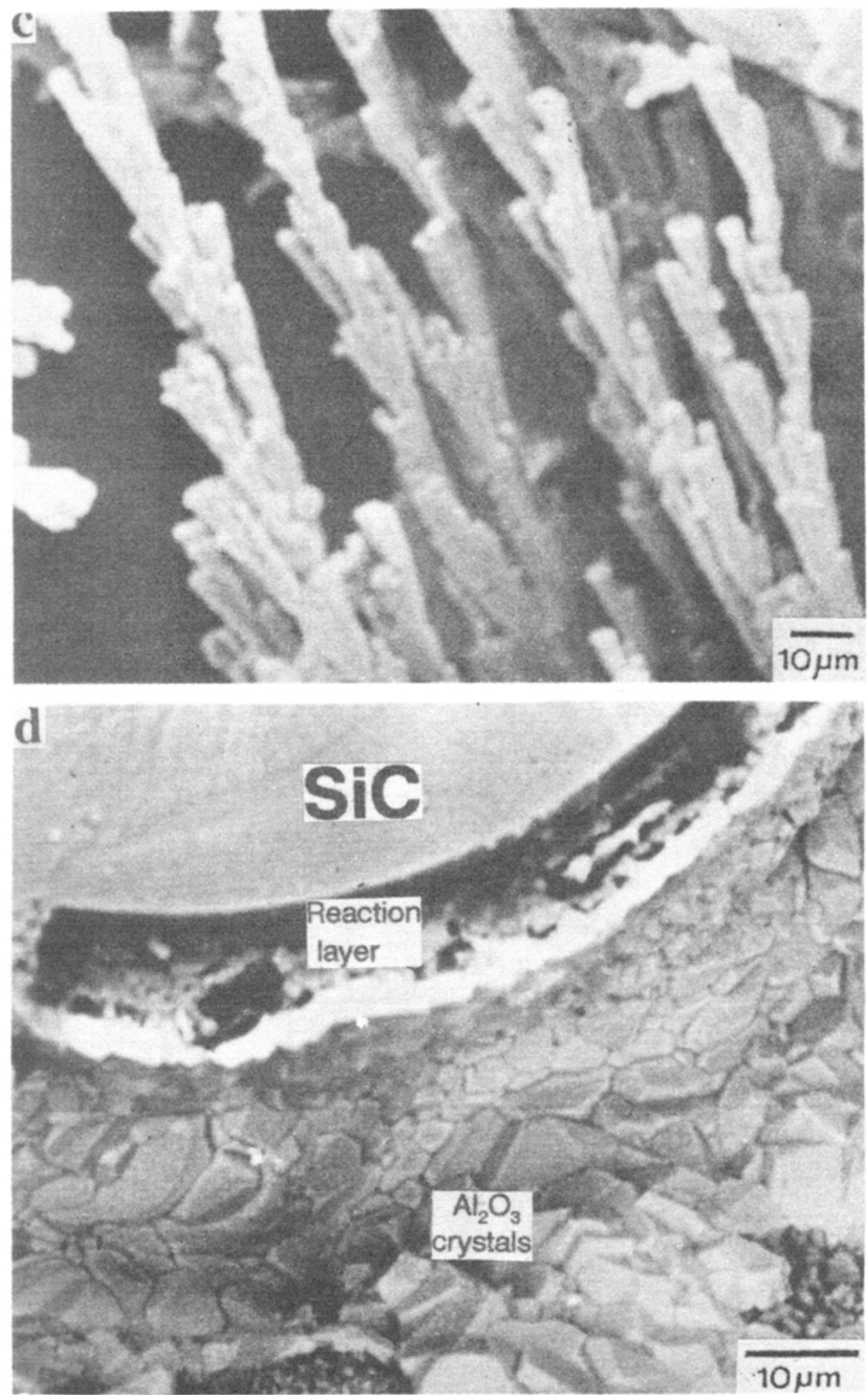

Figure 2. (a) Secondary nucleation of $\mathrm{Al}_{2} \mathrm{O}_{3}$ on the surface of a SiC particulate, (b) $\mathrm{ZnO}$ deposition on the surface of $\mathrm{SiC}$ fibre which was placed ahead of the reaction front, (c) growth of $\mathrm{Al}_{2} \mathrm{O}_{3}$ crystals during directed melt oxidation of a base alloy (without reinforcements) and (d) equiaxed $\mathrm{Al}_{2} \mathrm{O}_{3}$ crystals in a $\mathrm{SiC}$ fibre reinforced composite.

unalloyed composites. This is expected due to greater oxygen transport in the presence of $\mathrm{Ti}$ and $\mathrm{Zr}$ which can also modify the oxide layer morphology to some extent (Shida and Anada 1993). The microstructures of these composites (figure 4) also indicate the 


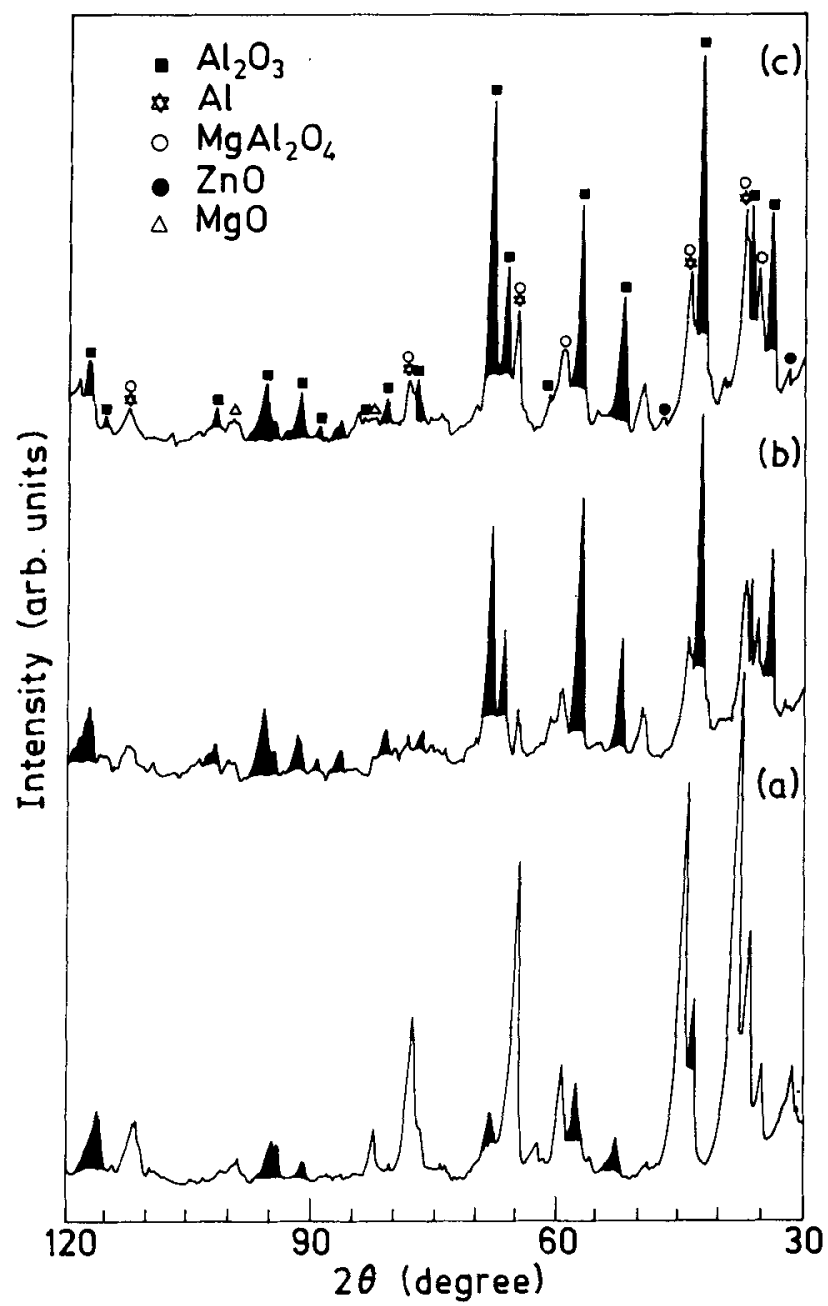

Figure 3. X-ray diffraction patterns obtained from directed melt oxidized composites obtained from oxidation of (a) $\mathrm{Al}-\mathrm{Zn}-\mathrm{Mg}$ alloys, (b) and (c) $\mathrm{Al}-\mathrm{Zn}-\mathrm{Mg}$ alloys doped with zirconium and titanium $(0.12 \mathrm{wt} \%)$ respectively.

refinement of composite structure in $\mathrm{Ti}$ and $\mathrm{Zr}$ containing composites. In addition to the microstructural refinement, there is also a variation in the metal to ceramic ratio in the alloyed samples. Alloying additions seem to modify both the ceramic matrix and the composition of the alloy retained in the matrix (Brevel et al 1993). Further, these additions form alloy constituents and/or intermetallics; depending on the nature of the phase, oxygen solubility changes. Normally reduced aluminium activity results in a high oxygen solubility (Johnson and Negelberg 1995). Earlier, Brevel et al (1993) also demonstrated that nickel additions to an $\mathrm{Al}-\mathrm{Si}-\mathrm{Sr}$ alloy change the composite microstructure.

Microstructural refinement in alloyed systems could be explained by examining the nucleation of $\mathrm{Al}_{2} \mathrm{O}_{3}$ in these composites. In directed melt oxidized alloys, solute atom concentration significantly affects the formation of $\mathrm{Al}_{2} \mathrm{O}_{3}$. For example, when $\mathrm{Mg}$ level 


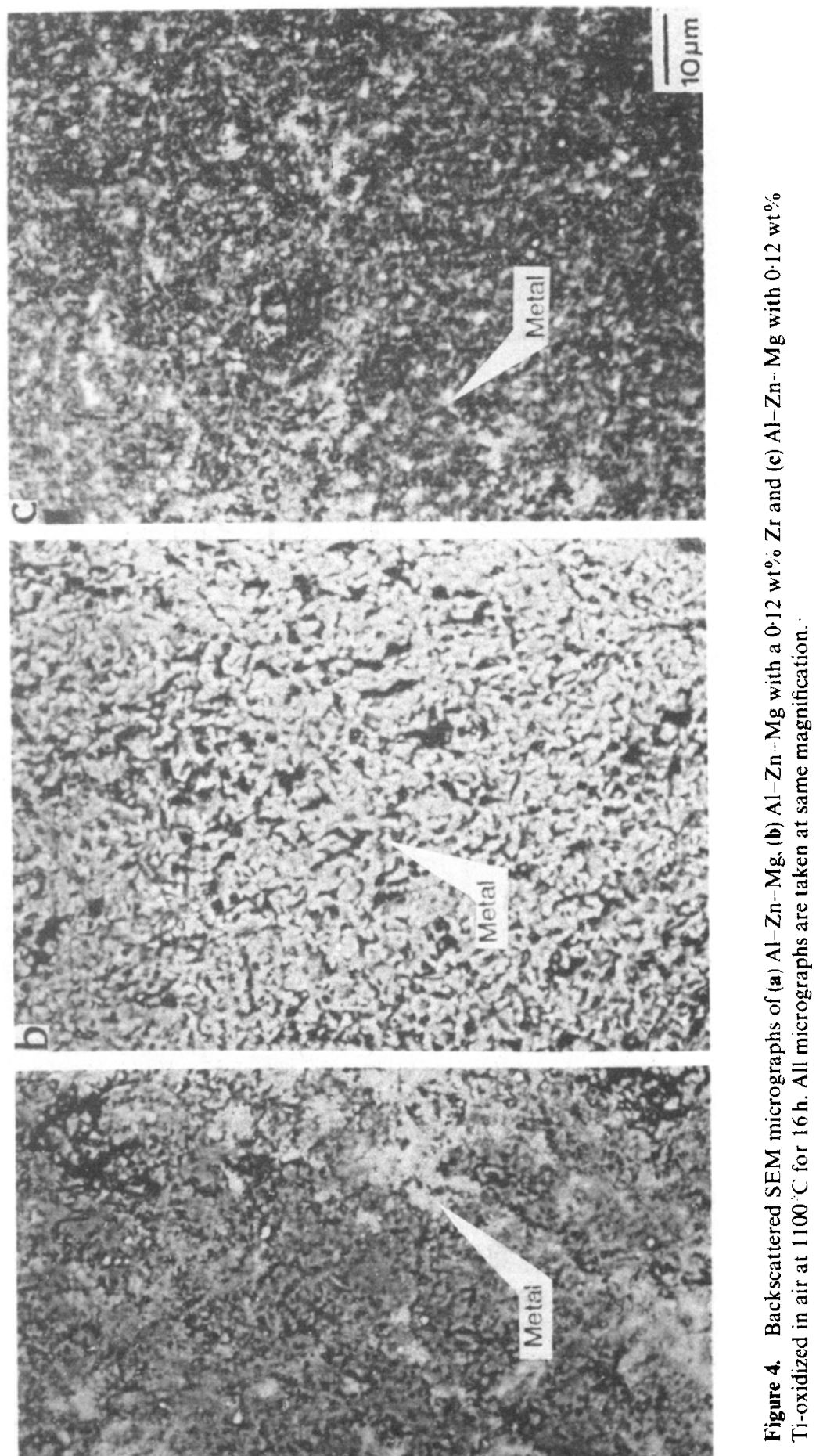


drops to $\mathrm{Al}_{2} \mathrm{O}_{3}+\mathrm{MgAl}_{2} \mathrm{O}_{4}$ phase field in $\mathrm{Al}-\mathrm{Mg}-\mathrm{O}$ phase diagram, the surface of the wicked nodules are covered with spinel, whereas inside the nodule $\mathrm{Al}_{2} \mathrm{O}_{3}$ begins to nucleate (Murthy and $\mathrm{RaO}$ 1995). Although the exact mechanism of $\mathrm{Al}_{2} \mathrm{O}_{3}$ nucleation is not clear, one probable route could be by dissociation of spinels, where $\mathrm{Al}_{2} \mathrm{O}_{3}$ precipitation occurs readily to grow as large crystals (Lewis 1969; Kingery et al 1991). As the $\mathrm{Mg}$ level still drops further (below $0.3 \mathrm{wt} \%$ ), $\mathrm{Al}_{2} \mathrm{O}_{3}$ nucleated earlier can continue to grow. Otherwise fresh $\mathrm{Al}_{2} \mathrm{O}_{3}$ crystals nucleate, since composition lies in the phase field of $\mathrm{Al}_{2} \mathrm{O}_{3}$. Fresh nucleation can occur on pores of $\mathrm{MgO}$, since the energy required for nucleation is minimum. Alloying additions of $\mathrm{Ti}$ and $\mathrm{Zr}$ must be influencing the nucleation of $\mathrm{Al}_{2} \mathrm{O}_{3}$ by one or more of the following mechanisms: (a) Ti and $\mathrm{Zr}$ may be getting adsorbed at the nucleation site and minimize the energy required for and/or (b) formation of $\mathrm{TiO}_{2}, \mathrm{ZrO}_{2}$ or their reaction products with other oxides present in the system can act as nucleation sites in the presence of $\mathrm{Mg}, \mathrm{Zn}$ etc. However, more detailed work is needed to establish the precise mechanism of nucleation. When $\mathrm{Zr}$ containing alloy is infiltrated into $\mathrm{SiC}$ fibre preform, combined effects viz. refinement through secondary nucleation and alloying. with fine dispersion of metal particles are seen (figure 5).

\section{Summary}

Modification of directed melt oxidized structures is possible either by external reenforcements or by alloy additions. In the present investigation, both methodologies have been tried using $\mathrm{SiC}$ monofilaments and alloying additions such as $\mathrm{Ti}$ and $\mathrm{Zr}$. The role of alloying addition is briefly discussed.

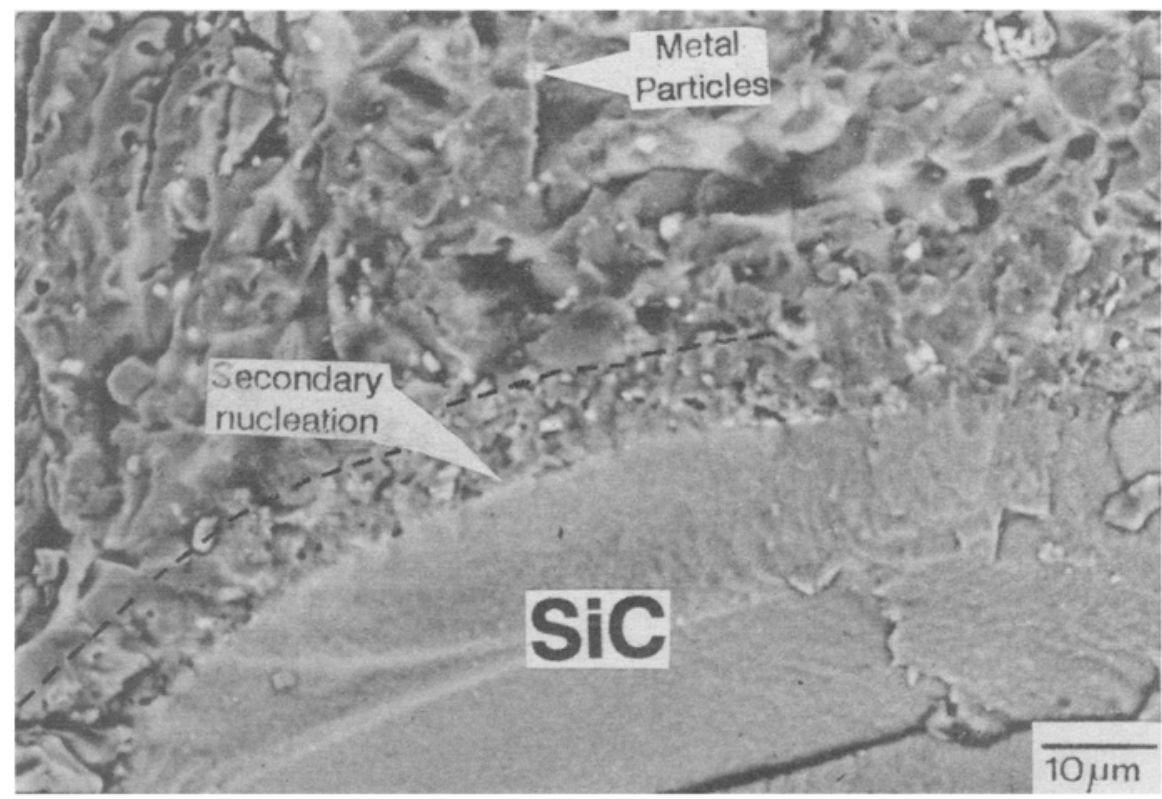

Figure 5. Composites structure after adopting both refinement methods viz. reinforcement with $\mathrm{SiC}$ fibre and alloving with $\mathrm{Zr}$. 


\section{Acknowledgement}

The financial help from BRNS, India (project no. 34/4/93-G) is gratefully acknowledged.

\section{References}

Breval E, Aghajanian M K, Biel J P and Antolin S 1993 J. Am. Ceram. Soc. 761865

Dhandapani S P, Jayaram V and Surappa M K 1994 Actu Met.\& Mater. 42649

Hanabe M, Jayaram V and Bhaskaran T A 1996 Acta Met.\& Mater. 44819

Johnson W B and Negelberg A S 1995 Phase diagrams in advanced ceramics (ed.) A M Alper (San Diego: Academic Press) p. 85

Kingery D W, Boewn H K and UhImann D R 1991 Introduction to ceramics (New York: John Wiley) p. 292 Lewis M H 1969 Philos. Mag. 20985

Manor E. Ni H, Levi C G and Mehrabian R 1993 J. Am. Ceram. Soc. 761777

Murthy V S R and Rao B S 1995 J. Mater. Sci. 303091

Murthy V S R and Deepak A 1996 Br. Ceram. J.\& Trans. 95173

Newkirk M S, Urquhart A W and Zwicker H R 1986 J. Mater. Res. 11

Newkirk M S, Lesher H D, White D R, Kennedy C R, Urquhart A W and Clarr T D 1987 Ceram. Engg. Sci Proc. 8879

Salas O, Ni H, Jayaram V, Vlach K C. Levi C G and Mehrabian R 1991 J. Mater. Res. 61964

Shida Y and Anada H 1993 Mater. Trans. JIM 3236 